Gut, 1973, 14, 711-715

\title{
Double-blind trial of deglycyrrhizinated liquorice in gastric ulcer
}

\author{
ALICE ENGQVIST, FREDRIK VON FEILITZEN, EINAR PYK, AND \\ HANS REICHARD \\ From the Medical Department IV and Radiological Department I, Södersjukhuset, Stockholm, Sweden
}

SUMMARY In order to investigate further the reported beneficial effect of deglycyrrhizinated liquorice in gastric ulcer, a trial with a double-blind, cross-over design was performed. The patients were treated during two consecutive periods of four weeks each with either liquorice extract during the first period and placebo during the second or placebo during the first period and liquorice during the second. Only patients with chronic ulcer disease were accepted for the trial. The dosage of the liquorice extract was $760 \mathrm{mg}$ three times daily. During the first period 38 patients with 47 ulcers in the ventricle and during the second period 30 patients with 36 ulcers took part in the trial. The patients' sex, age, site of the ulcer in the ventricle, and ulcer size in the groups treated with liquorice and placebo during periods I and II were similar. Nor could any difference be shown between the groups treated with liquorice and placebo with respect to heredity, duration of ulcer disease, alcohol consumption, smoking, or the use of drugs.

There was no tendency to quicker healing in either group as regards change of ulcer area or complete healing. Small ulcers healed more quickly than big ones. Ulcers at the angulus healed very poorly. No side effects of treatment were observed.

Our study was not able to demonstrate any healing effect of the liquorice extract (Caved-S) on gastric ulcer.

Carbenoxolone (synthesized from glycyrrhizinic acid, a glycoside extracted from liquorice) has been reported to have a healing effect on gastric ulcer (Doll, Hill, Hutton, and Underwood, 1962), but because it shows frequent side effects, such as liquid retention, elevation of diastolic blood pressure, hypokalaemia, and concomitant muscular weakness (Doll et al, 1962) it has not become widely used.

In a number of investigations only two of which were performed with a double-blind technique (Turpie, Runcie, and Thomson, 1969; Wilson, 1972), a deglycyrrhizinated extract of liquorice has been reported to accelerate the rate of healing in gastric ulcer. This extract has no side effects of clinical significance (Turpie et al, 1969; Cooke and Baron, 1971).

The aim of our study was to investigate further the reported beneficial effect of deglycyrrhizinated liquorice (Caved-S) in gastric ulcer.

\section{Methods}

The trial was conducted using a double-blind cross-

Received for publication 7 June 1973. over design. Each patient was treated for two consecutive periods of four weeks each either with liquorice extract during the first period and placebo during the second, or placebo during the first period and liquorice during the second. At the beginning of the first period and at the end of each period the patients were questioned and thoroughly investigated.

\section{Selection of Patients}

To obtain suitable patients for the study we wrote to physicians in the area served by our hospital who sent us patients with gastric ulcer willing to participate in the trial. The conditions for acceptance were ulcer niche visible on radiographs; at least three years of ulcer symptoms; age below 60 years; no other chronic disease; no evidence of alcohol or drug abuse; no suspicion of cancer. Two patients, aged between 60 and 65 years, were accepted and included in the trial. All patients were fully informed by one of us of the purpose of the investigation and about the conditions for participation. The patients were randomly allocated to start either with liquorice or placebo. 


\section{Liquorice Extract and Placebo}

The liquorice extract and placebo were distributed in identical capsules (kindly supplied by Cedona, Holland), which contained either $380 \mathrm{mg}$ deglycyrrhizinated liquorice, which is an ingredient of Caved-S, or candy-coloured lactose. The medicine was administered in bottles with 42 capsules each (one week's consumption). The dose was two capsules three times daily. During each period of treatment the patient received a letter reminding him of the medication. At the return visits a note was made of unused capsules.

\section{Other Therapy}

The patients were told to take an antacid preparation according to need and were advised not to smoke. All patients were requested not to take any other drugs than those approved by us. Anticholinergic drugs were explicitly forbidden. The patients stayed at home only when they considered that their symptoms warranted a sickness certificate. One of the patients was treated in hospital for 13 days because of severe ulcer pain during period II when he received placebo. All the others were treated as outpatients.

\section{Examinations}

At the patient's first visit a full history was obtained and a physical examination was performed. At each subsequent visit the symptoms, weight and blood pressure, erythrocyte sedimentation rate, analysis of haemoglobin and electrolytes, and urine analysis were recorded. All patients had free hydrochloric acid. At the subsequent visits after four and eight weeks the patients were questioned about the medication. At the end of the trial most of the patients underwent gastroscopy.

\section{Radiological Examination and Measurement of Ulcer Niche}

The radiological examination was performed not more than three days before the beginning of medication and a control radiograph was always taken within $28 \pm 3$ days. The projections were taken so that the maximum ulcer niche profile (depth $x$ maximal breadth) could be measured. The measurements were done by the same radiologist (E.P.). In patients with more than one ulcer at the same time the ulcer niche was calculated as the sum of the niche areas. The change in the ulcer size during each period was expressed as follows: (1) change in ulcer niche area expressed in $25 \%$ interval; (2) change in ulcer niche area in sq $\mathrm{mm}$ for each patient; (3) change in ulcer niche area as a percentage of original size for each patient (an increase of more than $100 \%$ was counted as $100 \%$ ).

\section{Registration of Data}

Data concerning the patients' sex, age, reliability concerning medication, heredity for ulcer disease, alcohol consumption, days off from work, duration of ulcer symptoms, side effects, findings at gastroscopy, site and size of the ulcer, effect of healing during periods I and II, epigastric pain, and results of laboratory tests were registered. Standard statistics were used.

\section{Comparison of the Groups Treated with Liquorice and Placebo}

The patients' sex and age, location of the ulcer in the ventricle, and ulcer size in the groups treated with liquorice and placebo during periods I and II are shown in tables I-IV. The two groups were similar

\begin{tabular}{llllll}
\hline & \multicolumn{2}{l}{ Number of Patients } & & \\
\cline { 2 - 3 } & Period I & & & Period II \\
\cline { 2 - 3 } \cline { 5 - 6 } & Liquorice & Placebo & & Liquorice & Placebo \\
\hline Male & 7 & 7 & 7 & 6 \\
Female & 13 & 11 & 7 & 10 \\
Total & 20 & 18 & 14 & 16 \\
\hline
\end{tabular}

Table I Sex of treated ulcer patients

\begin{tabular}{llllll}
\hline Age in Years & \multicolumn{2}{l}{ Number of Patients } & & \\
\cline { 2 - 3 } & \multicolumn{2}{l}{ Period I } & & & Period II \\
\cline { 2 - 3 } \cline { 5 - 5 } & Liquorice & Placebo & & Liquorice & Placebo \\
\hline$<40$ & 2 & 2 & 2 & 2 \\
$41-50$ & 5 & 5 & 3 & 4 \\
$51-60$ & 12 & 10 & 8 & 9 \\
$61-65$ & 1 & 1 & 1 & 1 \\
Total & 20 & 18 & 14 & 16 \\
\hline
\end{tabular}

Table II Age of treated patients

\begin{tabular}{|c|c|c|c|c|}
\hline \multirow[t]{3}{*}{ Site of Ulcer } & \multicolumn{4}{|c|}{ Number of Ulcers } \\
\hline & \multicolumn{2}{|l|}{ Period I } & \multicolumn{2}{|l|}{ Period II } \\
\hline & Liquorice & Placebo & Liquorice & Placebo \\
\hline $\begin{array}{l}\text { Prepyloric }{ }^{1} \\
\text { Canalis } \\
\text { Angulus }{ }^{1} \\
\text { Corpus }\end{array}$ & $\begin{array}{r}11 \\
3 \\
6 \\
5\end{array}$ & $\begin{array}{r}9 \\
1 \\
2 \\
10\end{array}$ & $\begin{array}{l}8 \\
0 \\
2 \\
7\end{array}$ & $\begin{array}{l}7 \\
2 \\
6 \\
4\end{array}$ \\
\hline Total & 25 & 22 & 17 & 19 \\
\hline
\end{tabular}

Table III Site of ulcer in treated patients

${ }^{1}$ Prepyloric denotes within $2 \mathrm{~cm}$ from pylorus. Angulus denotes within $1 \mathrm{~cm}$ from angulus. 


\begin{tabular}{|c|c|c|c|c|}
\hline \multirow[t]{3}{*}{ Area $(s q \mathrm{~mm})$} & \multicolumn{4}{|c|}{ Number of Patients } \\
\hline & \multicolumn{2}{|l|}{ Period I } & \multicolumn{2}{|l|}{ Period II } \\
\hline & Liquorice & Placebo & Liquorice & Placebo \\
\hline $\begin{array}{c}10-80 \\
81-160 \\
161-320 \\
>320\end{array}$ & $\begin{array}{r}11 \\
4 \\
3 \\
2\end{array}$ & $\begin{array}{l}8 \\
5 \\
3 \\
2\end{array}$ & $\begin{array}{l}6 \\
5 \\
2 \\
1\end{array}$ & $\begin{array}{l}9 \\
3 \\
3 \\
1\end{array}$ \\
\hline Total & 20 & 18 & 14 & 16 \\
\hline
\end{tabular}

Table IV Area of ulcer

with respect to these parameters, nor could any difference be shown between the groups treated with liquorice and placebo with respect to heredity, duration of ulcer disease, alcohol consumption, smoking, or the use of drugs.

\section{Multiple Ulcers}

Nine of the patients had two gastric ulcers at the same time during 15 periods of treatment in all. In all the nine cases one of the ulcers was prepyloric, ie, within $2 \mathrm{~cm}$ from the pylorus, while three of the others were situated in the canalis, four at the angle, ie, within $1 \mathrm{~cm}$ from the angle, and two in the corpus.

\section{Results}

CHANGE OF NICHE AREA DURING TREATMENT There has been no tendency to quicker healing in either group of treatment as regards change in ulcer area (table V). The number of completely healed

\begin{tabular}{|c|c|c|c|c|}
\hline \multirow[t]{3}{*}{ Ulcer Niche } & \multicolumn{4}{|c|}{ Number of Patients } \\
\hline & \multicolumn{2}{|l|}{ Period I } & \multicolumn{2}{|l|}{ Period II } \\
\hline & Liquorice & Placebo & Liquorice & Placebo \\
\hline $\begin{array}{l}\text { Decreased }>50 \% \\
\text { Decreased } 25-50 \% \\
\text { Unchanged }( \pm 25 \%) \\
\text { Increased } 26-50 \% \\
\text { Increased }>50 \%\end{array}$ & $\begin{array}{l}8 \\
7 \\
3 \\
0 \\
2\end{array}$ & $\begin{array}{l}8 \\
3 \\
5 \\
0 \\
2\end{array}$ & $\begin{array}{l}6 \\
1 \\
7 \\
0 \\
0\end{array}$ & $\begin{array}{l}7 \\
0 \\
6 \\
1 \\
2\end{array}$ \\
\hline Total & 20 & 18 & 14 & 16 \\
\hline
\end{tabular}

Table V Change in ulcer size during treatment

ulcers during period I was four in the liquorice group compared with five in the placebo group and the corresponding figures during period II were four and five respectively. Also when the reduction in ulcer size was classified according to the criteria above (table VI), there was no tendency to quicker healing in either group.

In 18 patients $(25 \%)$ the ulcers healed completely during the 68 periods of four weeks. The corresponding figure during period $I$ for ulcers of

\begin{tabular}{|c|c|c|c|c|}
\hline & \multicolumn{4}{|c|}{ Number of Patients } \\
\hline & \multicolumn{2}{|l|}{ Period I } & \multicolumn{2}{|l|}{ Period II } \\
\hline & Liquorice & Placebo & Liquorice & Placebo \\
\hline \multirow{3}{*}{$\begin{array}{l}\text { Number of patients } \\
\text { Average in size of ulcer at } \\
\text { the beginning (sq } \mathrm{mm} \text { ) } \\
\text { Average reduction (sq mm) } \\
\text { Average percentage } \\
\text { reduction }\end{array}$} & 20 & 18 & 14 & 16 \\
\hline & $\begin{array}{c}195 \\
84^{1}\end{array}$ & $\begin{array}{c}165 \\
16^{1}\end{array}$ & $\begin{array}{c}194 \\
39^{1}\end{array}$ & $\begin{array}{c}135 \\
17^{1}\end{array}$ \\
\hline & 37 & 36 & 46 & 29 \\
\hline
\end{tabular}

Table VI Reduction in ulcer size during treatment

'Statistical analysis using Wilcoxon's test (Brownlee, 1965) reveals no statistical difference between liquorice and placebo during periods I and II with regard to any of the parameters, $P>0.1$ (period I = 0.67 , period II $=1 \cdot 4$ ).

less than $100 \mathrm{sq} \mathrm{mm}$ is four out of nine ulcers $(45 \%)$ in the liquorice group and four out of $10(40 \%)$ in the placebo group that healed completely. Corresponding figures during period II were three out of eight $(40 \%)$ in the liquorice group and four out of 11 $(35 \%)$ in the placebo group.

In almost $50 \%$ of all patients the ulcers were reduced in size more than $50 \%$ during four weeks (one period). Only in seven of the 68 periods did the ulcer niche increase in size.

\section{HEALING TENDENCY AND ULCER LOCALIZATION}

There was no difference in healing between the ulcers in the corpus, canalis, and prepyloric part of the ventricle (table VII). On the other hand, the ulcers at the angulus healed poorly (table VII). Figure 1 is a graphic presentation with a comparison of the healing of ulcers at the angulus and in the corpus.

\begin{tabular}{lll}
\hline Site & Number of Ulcers & Number of Healed Ulcers \\
\hline Prepyloric & 35 & 12 \\
Canalis $^{2}$ & 6 & 1 \\
Angulus $^{2}$ & 16 & 0 \\
Corpus & 26 & 10 \\
Total & 83 & 23
\end{tabular}

Table VII Ulcer healing per four weeks' treatment with respect to site of ulcer

1Prepyloric denotes within $2 \mathrm{~cm}$ from pylorus.

'Angulus denotes $\pm 1 \mathrm{~cm}$ from angulus.

\section{SIDE EFFECTS}

Only one patient increased more than $3 \mathrm{~kg}$ in weight during one period of treatment, ie, during period II in the liquorice group. No increase in blood pressure of more than $30 \mathrm{~mm} \mathrm{Hg}$ systolic or $10 \mathrm{~mm} \mathrm{Hg}$ diastolic was observed. Blood pressure data were incomplete in nine and the weight data in 22 of the 68 periods of treatment. 

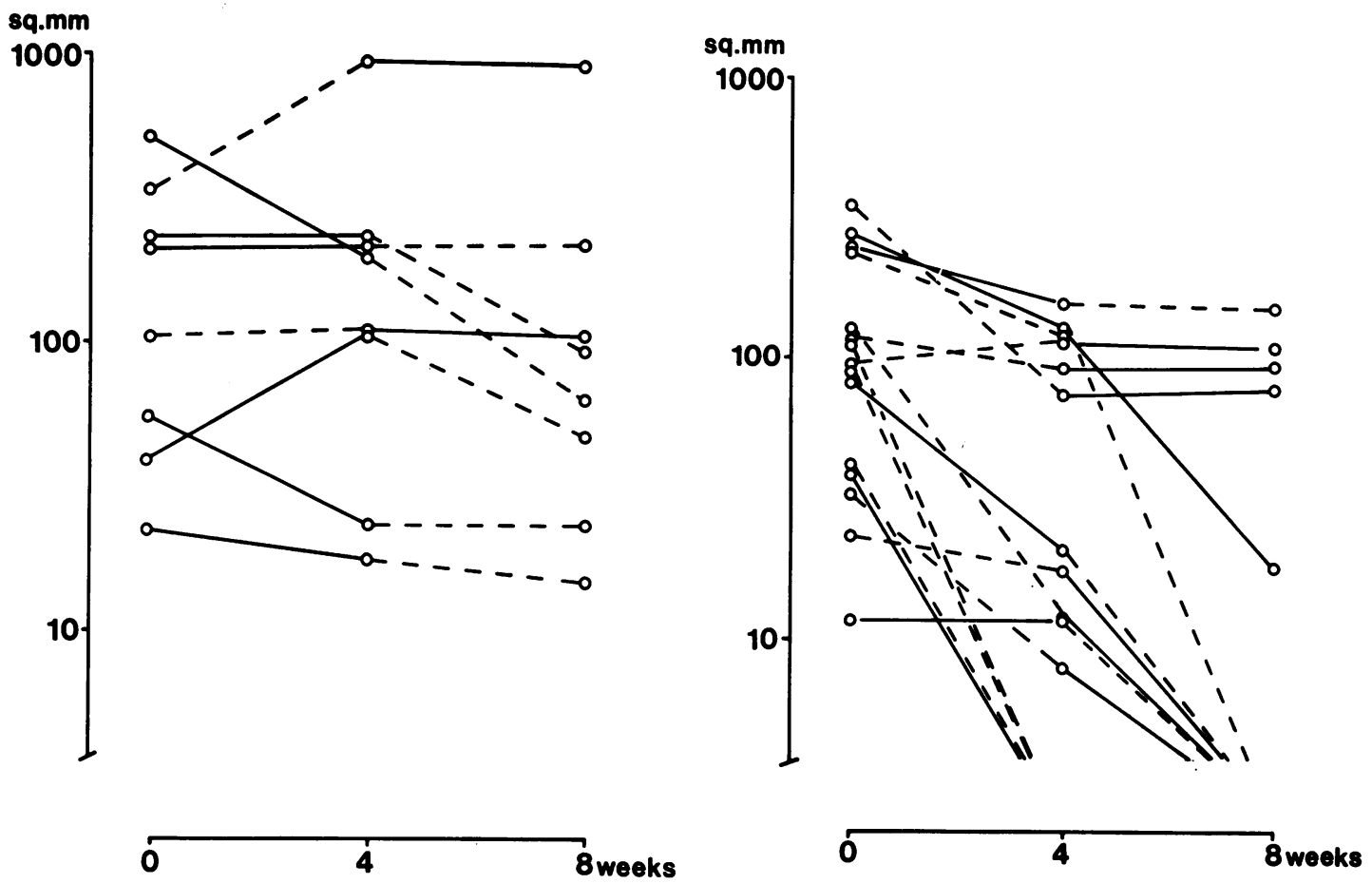

Fig Change in ulcer niche profile during two consecutive four-week periods of treatment. Note the almost unchanged size of ulcers at the angulus (left figure) and the decrease in size of ulcers of the corpus (right figure). Solid line = liquorice extract. Broken line = placebo.

\section{Discussion}

The effect of treatment was measured as the change in size of the ulcer niche observed radiologically. With the ordinary barium meal method the ulcers have to be seen in strict profile to make the measurement of niche size reliable. Our clinical trial was planned in cooperation with the radiological department and the radiological examinations were performed with special respect to the measurements of ulcer size. Nevertheless it was sometimes difficult to demarcate the niche from the surrounding mucosal wall. Another factor of uncertainty was that the niche could be partly filled with debris so that the contrast medium did not fill the whole ulcer crater. Also only two of the three dimensions of the ulcer were measured. The sources of errors, however, have been considered small, especially with respect to the division of the ulcer area change into intervals of $25 \%$ as is shown in table V. The sources of error have also affected the material at random.

We found that nine of the patients had two gastric ulcers at the same time during 15 periods of treatment altogether out of a total of 68 periods. Multiple gastric ulcers were found in $2.3 \%$ in a recent large cooperative study by the Veterans Administration of 638 patients (Gastroenterology, 1971) and in $5 \%$ of 100 patients studied by Palmer (1952). In these series the patients were examined radiologically. Higher figures for multiple gastric ulcers in series of patients with gastric ulcer were found in necropsy material by Portis and Jaffé(1938), by Dolphin, Smith, and Wangh (1953), and by others with figures around $20 \%$. It is possible that the high frequency of multiple gastric ulcers in our material reflects a well developed radiological technique.

In cases with more than one gastric ulcer we added up each patient's ulcer niche profiles instead of regarding each ulcer as a single observation unit. At the analysis of healing tendencies at different ulcer sites it was necessary to deal with each ulcer as a separate unit.

In this trial we have not been able to show any healing effect of the liquorice extract in contrast to the findings of Turpie et al (1969) who reported quicker healing of ulcers in their liquorice extract group.

A comparison between our work and that of Wilson (1972), who also reported an ulcer-healing effect of the liquorice extract, cannot be made because in the 
latter work the comparison is only between carbenoxolone and the liquorice extract without any placebo group.

Possible explanations for the differences between our results and those of Turpie et al are that we have used preparations with different biological activity, and differences in the selection of patients must also be considered. It seems unlikely that the manufacturer of the liquorice extract would have given us an inactive preparation. The manufacturer now has the opportunity to standardize the extract according to the improved biological method described by Andersson, Bárány, Caboclo, and Mizuno (1972).

The selection of patients with gastric ulcers is naturally of great importance for speed in healing. Sun and Stempien (1971) have shown that large ulcers heal more slowly than small ulcers. Our series indicate that ulcers at the angulus have a lesser healing tendency than other ulcers, an observation also reported by Bergemann, Heidinger, Schäfer, Rehs, and Oshima (1972). In the same way slow or nonexistent healing during an earlier period of treatment is prognostically a bad sign for healing during the following treatment period (Hanscom and Buchmann, 1971).

In a large study of the healing of gastric ulcers during treatment $80 \%$ of 320 ulcers of up to 100 sq $\mathrm{mm}$ (maximal ulcer profile) healed completely in six weeks and $60 \%$ had disappeared after three weeks of treatment (Sun and Stempien, 1971). It should be noted, however, that during the first three weeks the patients were treated in hospital.

Of our patients (who were all treated on an outpatient basis) with ulcers measuring less than 100 sq $\mathrm{mm}, 39 \%$ were healed within four weeks. The corresponding figure for the placebo group in Turpie's material is one of 13 patients, a surprisingly bad result. Many ulcers with a bad healing tendency such as angulus ulcers may by chance have been included in Turpie's placebo group.

We have in our trial worked with a somewhat larger series of patients than did Turpie et al (1969) and with the crossover technique the patients were treated in two periods of four weeks each. Thus we have almost doubled the number of treatment periods and to some extent we have also avoided a haphazard skewed distribution of the patient material.

References

Andersson, S., Bárány, F., Caboclo, J. L. F., and Mizuno, T. (1972). Protective action of deglycyrrhizinized liquorice on the occurrence of stomach ulcers in pylorus-ligated rats. Scand.J. Gastroent., 6, 683-686.

Bergemann, W., Heidinger, F. R., Schăfer, P. K., Rehs, H. V., and Oshima, H. (1972). Längere Ulcus-Verlaufsbeobachtungen anhand von Gastrokamerabildern. Paper read at 4th European Gastrocamera-Symposium, May, 1972, Berlin (Klinikum Steglitz der Freien Universitet, Berlin).

Brownlee, K. A. (1965). Statistical Theory and Methodology in Science and Engineering, 2nd ed., ch. 7. Wiley, New York.

Cooke, W. M., and Baron, J. H. (1971). Metabolic studies of deglycyrrhizinised liquorice in two patients with gastric ulcer. Digestion, 4, 264-268.

Doll, R., Hill, I. D., Hutton, C. F. R., and Underwood, D. J. (1962). Clinical trial of a triterpenoid liquorice compound in gastric and duodenal ulcer. Lancet, 2, 793-796.

Dolphin, J. A., Smith, L. A., and Waugh, J. M. (1953). Multiple gastric ulcers: their occurrence in benign and malignant lesions. Gastroenterology, 25, 202-205.

Hanscom, D. H., and Buchmann, E. (1971). Veterans Administration cooperative study on gastric ulcer. 4 . The follow up period. Gastroenterology, 61, 585-591.

Palmer, E. D. (1952). The clinical significance of the small benign gastric ulcer, with a note on benign ulcer of the greater curvature and in the absence of free hydrochloric acid. Amer. J. med. Sci., 223, 386-391.

Portis, S. A., and Jaffe, R. H. (1938). A study of peptic ulcer based on necropsy records. J. Amer. med. Ass., 110, 6-13.

Sun, D. C. H., and Stempien, S. J. (1971). Veterans Administration cooperative study on gastric ulcer. 3. Site and size of the ulcer as determinants of outcome. Gastroenterology, 61, 576-584.

Turpie, A. G. G., Runcie, J., and Thomson. T. J. (1969). Clinical trial of deglycyrrhizinized liquorice in gastric ulcer. Gut, 10, 299-302.

Wilson, J. A. C. (1972). A comparison of carbonoxolone sodium and deglycyrrhizinated liquorice in the treatment of gastric ulcer in the ambulant patient. Brit. J. clin. Pract., 26, 563-566. 